\title{
Evaluation of the propulsion technique and motor performance of wheelchair basketball players
}

\author{
Allan James de Castro BUSSMANN* \\ Márcia GREGUOL* \\ Emanuel Messias Oliveira de CARVALHO" \\ Felipe Arruda MOURA** \\ *Grupo de Estudos e \\ Pesquisa em Atividade \\ Física e Deficiência \\ (gepafid)Universidade \\ Estadual de Londrina, \\ Londrina, PR, Brasil. \\ **Laboratório de \\ Biomecânica Aplicada \\ Universidade Estadual \\ de Londrina, Londrina, \\ PR, Brasil.
}

\begin{abstract}
The objective of this study was to evaluate the propulsion technique of wheelchairs basketball athletes. The group of study was formed for 11 athletes practicing, the modality studied, with an average age of $30.27 \pm 6.51$ years. The sample was divided in two groups (faster, slowest) according to the performance in the agility and speed tests. To analyze the angular kinematics of the upper limbs, each person performed three attempts to "round trip" in a distance of 5 meters. The results indicate a strong positive association between the results obtained in the speed and agility tests $(r=0.83 ; p=0.002)$ and negative between speed test time and sports practice time $(r=-0.68 ; p=0.02)$. For the analysis of angular behavior significant difference was observed $(p=0.02)$, only in the variable maximum angle of the left elbow and the faster group presented the highest values. The angular behavior analyzes during all the movement, present significant difference at some point of the cycle, for the variables abduction angle on the left shoulder, absolute angle of the right and left forearm, absolute angles of the shoulder in the sagittal plane left and right, maximum angle of the right and left elbow. The results indicate that the athletes present specific characteristics of propulsion, and that some angular movement characteristics, as a smaller angle of shoulder abduction during early stages of the propulsion, influence the performance in the speed test.
\end{abstract}

KEYwORDS: Adapted sport; Biomechanics; Kinemetry; Performance.

\section{Introduction}

Over the years, adapted sports have made great progress, involving an increasing number of sports and attracting more professionals, athletes and media attention. This evolution is reflected in the level of competition, which demonstrates that adapted sport is no longer solely a therapeutic modality, but actually has strong characteristics focused on high performance. This fact has led to greater attention on more efficient strategies for training athletes, from physical conditioning to specific, technical and tactical aspects ${ }^{1}$.

Historically, amongst adapted sports, those practiced in wheelchairs have taken a prominent position, developing rapidly since the Second World $\mathrm{War}^{2}$. Much of this progress is due to the development of wheelchairs and the materials that compose them ${ }^{3}$.
Goosey-Tolfrey et al. ${ }^{4}$ pointed out that the complexity of wheelchair sports is a challenge for researchers. The authors also mention that the development of the athlete's wheelchair management skills is one of the most important aspects of the sports, as each of these, either with or without the use of additional implements, presents specificities that can be decisive for improved performance. Performance in these sports, therefore, depends primarily on two factors the athlete and the wheelchair - since it is the interaction between these elements that allows the wheelchair's propulsion and the specific movements of the various activities 5 .

Among the adapted sports for people with disabilities, a special mention should be given to 
wheelchair basketball, which is one of the oldest adapted sports, with a large number of practitioners worldwide ${ }^{6}$. Wheelchair basketball is characterized as an intermittent sport, which combines repeated intense efforts of short duration such as sprints, acceleration and deceleration and dynamic direction changes to maintain or obtain a position on the court $^{7}$. For success in this sport, the development of some physical capabilities is critical, for example speed, agility and muscular power ${ }^{5}$. Specifically with relation to the speed in wheelchair basketball, it depends not only on the athlete or the wheelchair, but on the relationship between them, since this relationship is essential for performance in the sport ${ }^{8}$.

Although there is a general consensus on training strategies to improve athletic results in wheelchair basketball, few coaches understand the benefits that technical aspects of propulsion can bring to the performance? ${ }^{9}$. In order to investigate the movement of athletes in wheelchairs, scientists have

\section{Method}

\section{Participants}

The study included 11 male wheelchair basketball athletes, aged between 20 and 38 years old, with spinal cord injuries but without involvement of the upper limbs (thoracic and lumbar neurological levels). The athletes practiced wheelchair basketball twice a week for two hours per session and participated in regional and national competitions of the sport. To participate in the study, all subjects had to have had a minimum of six months of sports practice and two years of spinal injury. Individuals who exhibited associated physical conditions that hindered the execution of the proposed tests were excluded from the sample. This study was approved by the Research Ethics Committee of the State University of Londrina, (approval number 170/2011).

\section{Data collection}

In this study, we analyzed the angular kinematics of the upper limbs during wheelchair propulsion over a 5-meter-long straight pathway on the basketball court. Each subject performed three trials, both outward and return, in order to collect images of both limbs to enable the reconstruction been investigating different factors that can influence the propulsion technique, such as, the synchronicity, symmetry, the contact force between the hand and the rim propulsion, optimization of the wheelchair settings and upper limb kinematics ${ }^{10}$.

Kinemetry is very useful for such analysis, because it allows the visualization of individual components from the same visual observation, enabling the quantification of the observed joint angles ${ }^{6}$. Quantitative biomechanical analysis of performance parameters provide information not only about the overall result (product) of analyzed motor task, but also the way (process) the task is performed ${ }^{10}$.

Therefore, research on the subject is necessary in order for professionals to understand the kinematic factors of wheelchair propulsion which are associated with the high velocity of the athlete. Thus, the aim of this study was to evaluate the propulsion technique of wheelchair basketball athletes, associating movement patterns with results obtained in speed and agility tests.

of the $3 \mathrm{D}$ motion. The movement cycle in this study was defined as starting with the first hand contact with the wheelchair handrims and finishing with the last moment that preceded a new contact. For the analysis, the cycles were randomly selected, discarding the first and last cycles of the pathway. For the test, athletes used their specific basketball wheelchairs and they were instructed to run the course at the highest possible speed.

\section{Kinematic analysis}

Two digital cameras fixed on tripods were used, which framed the whole environment for data collection and the camera functions used to record the actions of the participants included; using a frequency of $30 \mathrm{~Hz}$ acquisition, shutter $1 / 725$ and manual focus. After transferring the images to a computer, using the software DVideo ${ }^{11}$, we deinterlaced the images and measured specific anatomical points. The synchronization between the images from the two cameras was made using the identification of a common event in the images, for example, a frame in which the hand of the participant touched the wheelchair handrim.

The measurement process consisted of projecting a sequence of frames onto the computer 
screen, followed by automatic identification of all the points of interest of the athlete's body. For measurement, three passive reflective markers $(2.0 \mathrm{~cm}$ diameter) were positioned on the following anatomical points of both the upper limbs: (1) shoulder - greater tuberosity of the humerus; (2) elbow - lateral epicondyle of the humerus; and (3) Wrist - styloid process of the ulna. These three markers were used to define the individual segments of the arm and forearm.

The calibration of the cameras was carried out by positioning a topographic bar at a vertical level into ten different points of the data collection environment. This bar had markings along its length, with known distances between them. The reference system was then defined from the origin as follows: the $\mathrm{z}$-axis was determined as the vertical direction and directed upwards. The y-axis was orthogonal to the z-axis directed horizontally, representing movements in the medial-lateral direction. The $x$-axis was defined by the cross product of $y$ and $\mathrm{z}$, representing the movement in the anteroposterior direction. From these measurements and the calibration parameters, the 3D coordinates of the points were obtained using the DLT method ${ }^{12}$ and smoothed by loess function ${ }^{13}$.

To determine the accuracy of the study, we moved a rigid bar around the data collection environment with spherical markers at its extremities. The distance between the markers was known, having been measured with a paquimeter. After digitalization of these markers as a function of time in the software DVideo, we calculated the random and the systematic error and the accuracy value (calculated as the square root of the sum of squared errors) was found to be $0.59 \mathrm{~cm}$.

The variables analyzed in this study were defined as follows:

a) Shoulder abduction/adduction absolute angle: in the frontal plane, the angle between the longitudinal axis of the arm and a vertical reference line, originating at the shoulder marker. In the neutral position, this absolute angle had a zero value.

b) Shoulder flexion/extension absolute angle: in the sagittal plane, the angle between the longitudinal axis of the arm and a vertical reference line, originating at the shoulder marker. In the neutral position, this absolute angle had a zero value. Likewise, negative values represented shoulder extension and positive values represented flexion. c) Elbow relative angle: the angle formed between the longitudinal axes of the upper arm and forearm.

d) Attack angle: in the sagittal plane, the absolute angle formed between the longitudinal axis of the forearm and a vertical line of reference, with the origin at the elbow marker. In this case, positive angle values indicated that the forearm was ahead of the imaginary line passing through the axis of the elbow, while negative values indicated that the limb was rearward of this line.

e) Cycle duration: defined as the time interval (in seconds) between the first hand contact with the wheelchair handrim and the new contact in the consecutive propulsion.

From these variables, some specific values were identified: angle of peak extension and abduction of the shoulder during the cycle (called the recovery angle), the absolute angle of the shoulder at the time of attack (values of adduction/abduction and flexion/extension angles at the instant where the hands touched the wheelchair handrims) and the peak value of the relative elbow angle.

\section{Analysis of the motor performance}

With regard to motor performance, we also evaluated the speed and agility of the athletes in the wheelchairs. To evaluate agility, we applied the zigzag test from the Texas Fitness Test battery, which had a modified route for execution in a wheelchair ${ }^{14}$. The adaptation consisted of increasing the path distances of $3.8 \mathrm{~m} \mathrm{x} 4.0 \mathrm{~m}$ (original measurements) to $6.0 \mathrm{~m} \mathrm{x} 9.0 \mathrm{~m}$, whilst keeping the original layout. The purpose of the test is that its distance, which requires changes in direction, is covered with as much speed and efficiency as possible. Each athlete performed the route five times, the first time at a slow speed to familiarize themselves with the course, the second at maximum speed also for familiarization and the following three at maximum speed for registration. The time in seconds of the best attempt was considered for this study. Course tracing is detailed in FIGURE 1.

The athletes speed was assessed by means of a 20 meter sprint test. The test consisted of a 20 meter straight course, which was covered at maximum speed. The athletes had three attempts at the test, and the time in seconds of the best attempt was recorded. 


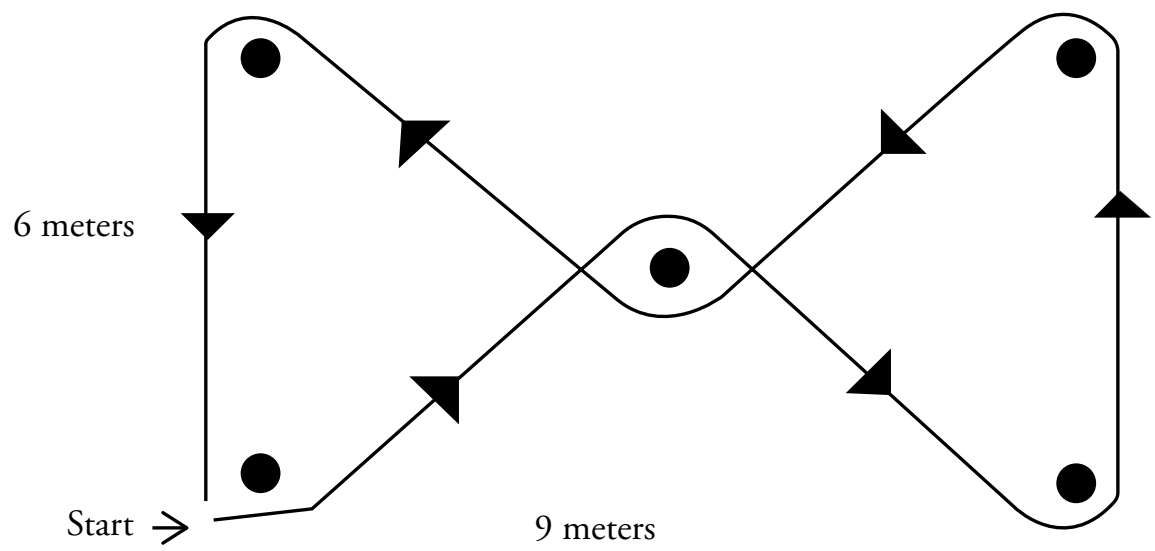

FIGURE 1 - Modified zigzag route test ${ }^{11}$.

After calculating the median value of the results obtained in the speed test, athletes were divided into two groups: "faster", consisting of 6 subjects who had completed the test in a time equal to or less than the median, and "slower", consisting of five subjects who had completed the test in a time greater than the median ( 5.8 seconds). Then, the kinematics data were evaluated separately for both groups.

\section{Statistical analysis}

The data were initially treated by means of descriptive statistics. We performed the Spearman correlation test to verify possible associations between age, time of practice, time of injury and motor performance. The successive $t$ test or Wilcoxon rank-sum tests were also conducted to find possible differences in movement angles between the faster and slower subjects. In all cases, the significance level adopted was $\mathrm{p}<0.05$. Analyses were performed using the software SPSS 15.0.

To compare the angular variables throughout the movement between the faster and slower subjects, the curves of each variable were normalized according to the movement cycle. Thus, for each time instant, the independent samples t-tests or Wilcoxon rank-sum tests were conducted when the samples presented normal or non-normal distribution, respectively.

\section{Results}

The mean age of the study participants was $30.27+6.51$ years (minimum of 20 and maximum of 38 years) and the mean time of practicing wheelchair basketball was $6.24+4.15$ years (minimum of 2 and maximum of 15 years). The general characteristics of the participants are detailed in TABLE 1.

The results for the speed and agility tests in wheelchairs are described in TABLE 2.

TABLE 1 - Characteristics of participants according to clinical variables

\begin{tabular}{lcc}
\hline Variables & $\mathbf{N}$ & $\%$ \\
\hline Etiology of trauma & & \\
Firearm & 5 & 45,5 \\
Automobile accident & 5 & 45,5 \\
Diving & 1 & 9,1 \\
ASIA Classification & & \\
A & 8 & 72,7 \\
B & 2 & 18,2 \\
C & 1 & 9,1 \\
\hline
\end{tabular}


Continuação

TABLE 1 - Characteristics of participants according to clinical variables

\begin{tabular}{lll}
\hline Variables & $\mathbf{N}$ & $\mathbf{\%}$ \\
\hline Injury Level & & \\
T3 a T8 & 2 & 18,2 \\
T9 a L2 & 9 & 81,8 \\
\hline
\end{tabular}

TABLE 2 - Descriptive values of the speed and agility tests in wheelchair

\begin{tabular}{lcc}
\hline Tests* & Agility & Speed \\
\hline Mean & 17,03 & 5,90 \\
Standard deviation & 1,14 & 0,51 \\
Median & 17,02 & 5,8 \\
Minimum value & 15,12 & 5,21 \\
Maximum value & 18,56 & 6,84 \\
\hline
\end{tabular}

Through the correlation analysis between motor performance variables, age and years of practice, there was a strong correlation between the results obtained in the speed and agility tests $(r=0.83$, $\mathrm{p}=0.002)$ and a negative correlation between the result of speed test time (in seconds) and the time of sports practice (in years) $(\mathrm{r}=-0.68, \mathrm{p}=0.02)$. These data indicate that performance in the agility and speed tests correlates significantly and that the longer the experience in the sport, the better the performance in the speed test in the wheelchair.

TABLES 3 and 4 illustrate, the left and right upper limb respectively, the specific values obtained by the "faster" and "slower" athletes in the variables: peak elbow relative angle, shoulder abduction angle attack moment, attack angle, shoulder extension attack moment, shoulder abduction - recovery angle, shoulder extension - recovery angle and cycle duration.

TABLE 3 - Mean values of the angular behavior for left and right limb (values expressed in degrees)

\begin{tabular}{|c|c|c|c|c|}
\hline Variables & $\begin{array}{c}\text { Faster } \\
(\text { left limb) }\end{array}$ & $\begin{array}{c}\text { Faster } \\
\text { (right limb) }\end{array}$ & $\begin{array}{c}\text { Slower } \\
\text { (left limb) }\end{array}$ & $\begin{array}{c}\text { Slower } \\
\text { (right limb) }\end{array}$ \\
\hline Peak elbow relative angle & $154,38 \pm 2,58 *$ & $127,42 \pm 61,28$ & $148,09 \pm 10,12$ & $144,51 \pm 11,62$ \\
\hline $\begin{array}{l}\text { Shoulder abduction angle - } \\
\text { attack moment }\end{array}$ & $62,06 \pm 8,30$ & $61,08 \pm 13,53$ & $67,79 \pm 9,85$ & $55,44 \pm 20,38$ \\
\hline Attack angle & $-1,34 \pm 9,22$ & $4,15 \pm 10,39$ & $4,09 \pm 3,75$ & $9,32 \pm 9,81$ \\
\hline Shoulder extension - attack moment & $-75,78 \pm 5,87$ & $-78,25 \pm 6,11$ & $-76,91 \pm 7,43$ & $-74,871 \pm 7,17$ \\
\hline Shoulder abduction - recovery angle & $70,85 \pm 13,19$ & $76,87 \pm 18,42$ & $76,69 \pm 7,28$ & $69,84 \pm 22,11$ \\
\hline Shoulder extension - recovery angle & $-80,18 \pm 7,88$ & $-83,66 \pm 8,32$ & $-81,38 \pm 6,84$ & $-82,44 \pm 10,81$ \\
\hline Cycle duration (seconds) & $0,51 \pm 0,03$ & $0,51 \pm 0,03$ & $0,47 \pm 0,05$ & $0,47 \pm 0,05$ \\
\hline
\end{tabular}

$*: p<0,05$ (Faster $X$ Slower athletes for the left limb).

TABLE 4 - Mean values of the angular behavior for right limb (values expressed in degrees)

\begin{tabular}{lcc}
\hline Variables & Faster & Slower \\
\hline Peak elbow relative angle & $127,42 \pm 61,28$ & $144,51 \pm 11,62$ \\
Shoulder abduction angle - attack moment & $61,08 \pm 13,53$ & $55,44 \pm 20,38$ \\
Attack angle & $4,15 \pm 10,39$ & $9,32 \pm 9,81$ \\
Shoulder extension - attack moment & $-78,25 \pm 6,11$ & $-74,871 \pm 7,17$ \\
Shoulder abduction - recovery angle & $76,87 \pm 18,42$ & $69,84 \pm 22,11$ \\
Shoulder extension - recovery angle & $-83,66 \pm 8,32$ & $-82,44 \pm 10,81$ \\
Cycle duration & $0,51 \pm 0,03$ & $0,47 \pm 0,05$ \\
\hline
\end{tabular}

*: Time expressed in
seconds.

(1) 
In order to verify any possible association between the observed movement and performance in the speed test we conducted the independent samples t-test. A significant difference $(p=0.02)$ was observed only in the variable maximum angle for the left elbow, and the faster group presented the highest values.

FIGURE 2 shows the angular behavior of the right and left upper limbs for a complete movement cycle in the wheelchair for both groups. The curved behavior of the variables associated with the speed allowed us to verify the behavior of the groups throughout the movement. The horizontal bars near the $\mathrm{X}$ axis represent the moments in the cycle in which there were significant differences.

For the shoulder abduction angle, no differences were found between the groups for the right limb. On the other hand, for the left limb, there were differences in the moment $20 \%-32.5 \%$ of the cycle, with higher values for the slower group. The curves of the behavior of the forearm absolute angle show differences in the moment $30 \%-85 \%$ of the cycle in the right limb, with lower values for the faster group. In the left limb we observed a difference at $100 \%$ of the cycle, again with the highest mean values for the faster group.

Comparing the absolute shoulder angles in the sagittal plane, differences were found between the groups at $47.5 \%-62.5 \%$ of the cycle in the right limb, with lower values for the faster group, and in the left limb at 15\%-62.5\% of the cycle, also with higher values for the faster group. Comparing the maximum elbow angle, the values of the curves indicate differences in the moment from $37.5 \%$ to $47.5 \%$ and $67.5 \%$ and $75 \%$ of the cycle in the right limb, with higher values for the slower group. In the left limb, differences were observed at $0 \%$ to $7.5 \%, 47.5 \%$ to $55 \%$ and $72.5 \%$ to $100 \%$ of the cycle, also with higher values for the slower group.
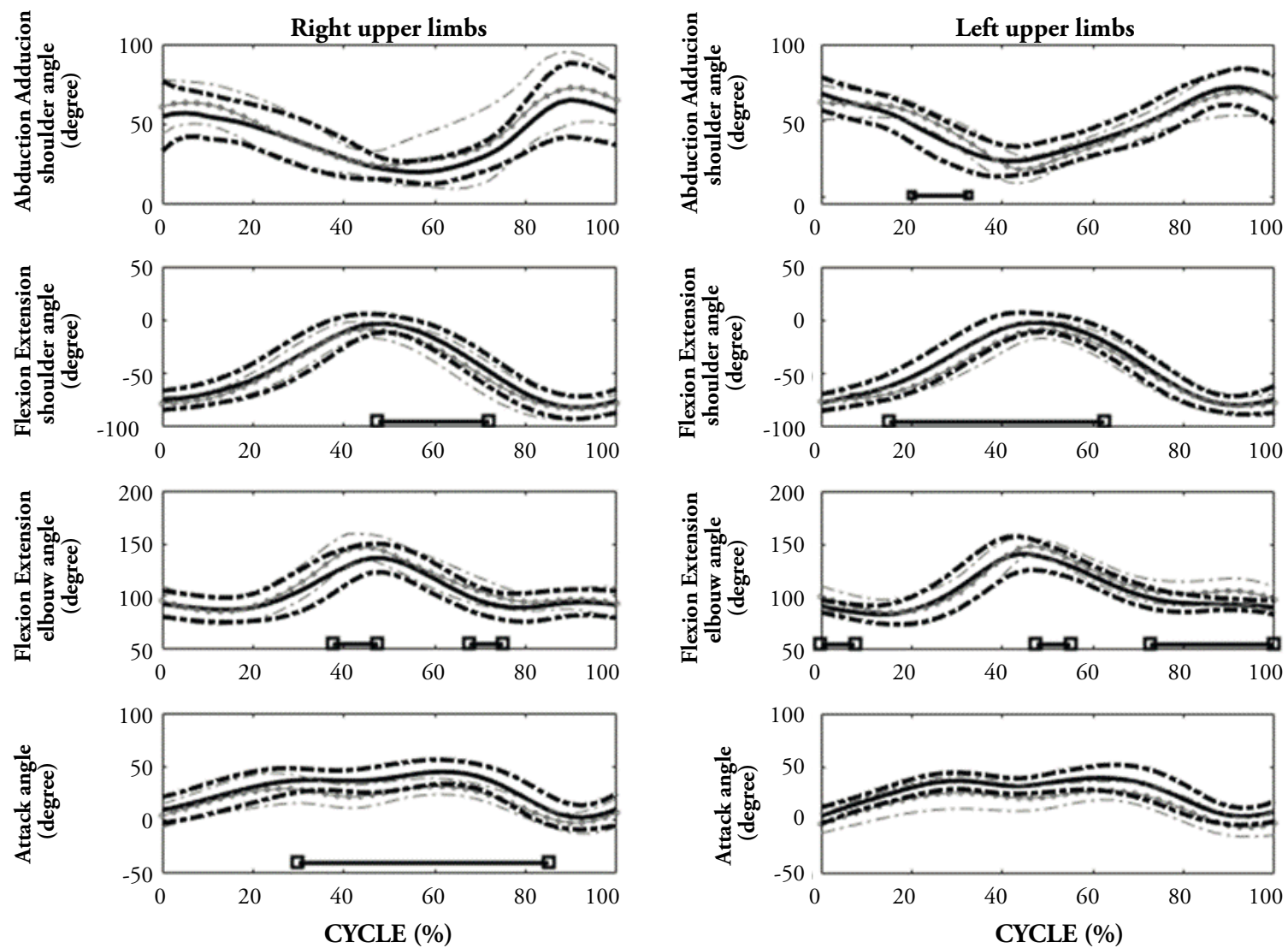

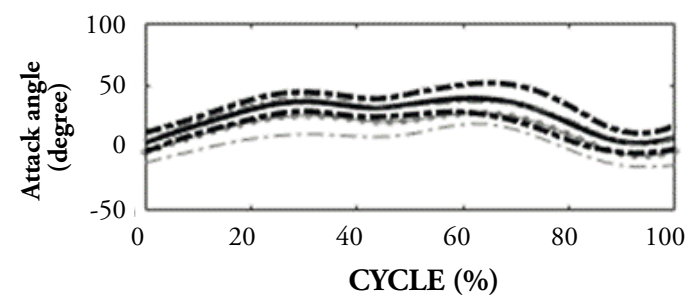

Slower group

Faster group

FIGURE 2 - Angular behavior during the propulsion movement cycle in wheelchair basketball players. 


\section{Discussion}

All individuals who took part in the study had spinal injuries in the thoracic and lumbar neurological levels, the majority $(81.8 \%, \mathrm{n}=9)$ between levels T9 and L2. These lesion levels were interesting for the analysis, due to the intention to assess movement patterns of athletes in wheelchairs without interference from motor restrictions in the upper limbs.

The results obtained in the speed and agility tests are similar to those presented in other studies conducted in athletes with spinal cord injuries at similar levels ${ }^{7,14-16}$. Tests of this nature are important at different moments in the training macro cycle, since the results obtained may provide information about the physical condition of the athletes, which are useful for the coaches to better direct the physical preparation of athletes ${ }^{7,17}$.

WB is characterized as a sport in which one aims to obtain and maintain a position in the court, by performing sprints movements, acceleration, deceleration and dynamic changes of direction ${ }^{7}$. Therefore, the athlete's performance in speed and agility tests, besides serving as an evaluation parameter of the training is critical to the sport performance. For example, the wheelchair basketball rule allows the athlete to cross the route of the opponent ${ }^{18}$. This will not be lacking if the axis of the back wheel can be seen in the front of the chair of his oponent ${ }^{18}$. Therefore, faster and more agile athletes gain advantage by disputing position on the court during the game.

The kinematic analysis of athletes during wheelchair propulsion provided relevant information about the angular and temporal behavior of the movement cycle. In this study, we chose to quantify the kinematic variables of the propulsion technique of wheelchairs on the court, conditions similar to those where athletes are used to playing. Although the collection was not performed in a controlled laboratory environment, the test accuracy showed a value of $5.9 \mathrm{~mm}$. Values found in the literature for different systems of kinematic analysis showed an accuracy of between $0.5 \mathrm{~mm}$ and $11.6 \mathrm{~mm}$, but were collected in a controlled environment ${ }^{19}$. Thus, the accuracy of this study can be considered satisfactory, given the conditions of data collection and the values reported in the literature.

The results were analyzed in two ways: the first was made in specific moments of the cycle, comparing the angular behavior between the left and right limbs and between the faster and slower groups. Another analysis was performed throughout the cycle, comparing the behavior between the faster and slower groups. Once in possession of such information, we sought to establish possible associations between the observed motion and motor performance.

According to VANLANDEWIJCK et al. ${ }^{8}$, wheelchair propulsion is divided into two phases. The phase of the attack is defined as that force production related to the hand contact with the rim. The next step is called the recovery phase, understood as a nonpropulsive phase, which occurs while the hand is positioned to restart the attack. The kinematics data showed the angular behavior of the upper limbs of athletes during the movement. When analyzing the results of the "faster" and the "slower" groups, the right and left limbs presented different behaviors. These data indicate that, unlike the assumption, wheelchair propulsion is not exactly a symmetrical task. However, the fact that the angular behavior was measured in cycles and at different times may have influenced the results ${ }^{20}$.

BERGAMINE et al. ${ }^{10}$ analyzed the performance of WB young players BCR in $20 \mathrm{~m}$ test using inertial measures units to check some biomechanical performance indicators. The symmetry between upper limbs during the propulsion phase is strongly related to better performance in the $20 \mathrm{~m}$ test. According to the authors, the execution of a more symmetrical and synchronized propulsion is associated with a higher speed and higher output power for propulsion cycles. Furthermore, authors state that the presence of an asymmetry in the upper limbs during the wheelchair propulsion can contribute to the development of injuries and there is a close relationship between upper limbs coordination, technical efficiency and injury prevention. Therefore, the symmetry when propelling the wheelchair is critical for optimal performance and decreased risk of injury.

One of the parameters of motion that was evaluated asymmetrically was the shoulder abduction during propulsion, which showed different behavior between the right and left limbs. Although in the right limb no angular differences between the slower and faster athletes were found, for the left limb differences were observed at the beginning of the cycle (FIGURE 2), with faster 
athletes showing lower values of this angle. Mason et al. ${ }^{3}$ analyzed wheelchair track and field athletes and also found that faster athletes exhibited smaller angles of shoulder abduction at the time of the attack. Thus, there seems to be a tendency for athletes in wheelchairs to perform faster movements with a smaller angle of shoulder abduction during early stages of the propulsion.

According to VANLANDEWIJCK et al. ${ }^{21}$, each athlete has their own propulsion technique. Still VANLANDEWIJCK et al..$^{21} \mathrm{e}$ DALLMEIJER et $\mathrm{al} .{ }^{22}$ indicate that experienced athletes can change their propulsion technique since upper limb is free to choose where to return to the ring. According to the authors, propulsion technique is determined by the recovery phase, i.e., the point where the athlete will touch the ring to start the new attack phase depends on the recovery movement. Experienced athletes can alter their propulsion technique according to the purpose of displacement, completing the recovery phase and resuming the rim propulsion at different times and positions.

When comparing the angular behavior and performance in speed tests, significant differences were found in maximum elbow angle, with higher speeds in the faster group showing lower angle values. These results indicate that faster athletes present greater elbow extension at the end of the attack, but at the beginning of the attack this joint is more flexed, which explain slower values for the forearm absolute angle.

When analyzing the curves with respect to motor performance, the differences appear only in the middle of the cycle. At this point, the forearm absolute angle for faster athletes, as well as the elbow relative angle presented lower values. In practical terms, this group performs the attack on the most backward position of the rim and with the elbow more flexed.

Shimada et al..$^{23}$ report that change occurs in the athlete's propulsion style as velocity increases. In this regard, VANLANDEWIJCK et al. ${ }^{8}$ indicate that the speed increase is related to the reduction of cycle and attack duration. However, this reduction does not influence the attack absolute angle, since the players do not want to change the angle magnitude, independent of this condition.

Understanding propulsion in a wheelchair is important for a number of reasons, such as injury prevention, optimization of sports performance and promotion of overall quality of life. The results presented on the angular behavior show that, for the investigated athletes, some movement patterns observed may be associated with a faster displacement. However, the challenge for coaches is to develop the best propulsion technique that generates more effective displacements whilst not increasing the risk of injuries to the athletes.

A possible limitation of the study was the small number of participants, which may have hindered some analysis. However, it should be noted that the 11 individuals evaluated correspond to the total number of athletes with spinal cord injury from wheelchair basketball teams in the cities of Londrina and Maringa. For this reason, the data collected may be of relevance to provide information for adapted sports professionals, as well as raising the issue of the importance of specific physical training for improved performance and injury prevention in sports.

\section{Resumo}

\section{Avaliação da técnica de propulsão e desempenho motor de jogadores de Basquetebol em cadeira de rodas}

0 objetivo deste estudo foi avaliar a técnica de propulsão de atletas de basquete em cadeira de rodas. Participaram do estudo 11 atletas praticantes da modalidade, com idade média de 30,27+6,51 anos. A amostra foi dividida em dois grupos (mais rápidos; mais lentos) de acordo com o desempenho nos testes de agilidade e velocidade. Para a análise da cinemática angular dos membros superiores cada sujeito realizou três tentativas com "ida e volta" em um percurso de 5 metros. Os resultados indicam forte associação positiva entre os resultados obtidos nos testes de velocidade e de agilidade $(r=0,83$; $p=0,002)$ e negativa entre tempo no teste de velocidade e tempo de prática esportiva $(r=-0,68$; $p=0,02)$. Para a análise do comportamento angular foi observada diferença significativa $(p=0,02)$ apenas na variável ângulo máximo do cotovelo esquerdo, com os atletas mais rápidos apresentando os maiores valores. A análise do comportamento angular durante todo o movimento apresentou diferenças 
significativas em algum momento do ciclo para as variáveis ângulo de abdução do ombro esquerdo, ângulo absoluto do antebraço direito e esquerdo, ângulos absolutos de ombro no plano sagital direito e esquerdo, ângulo máximo do cotovelo direito e esquerdo. Os resultados indicam que os atletas apresentam características específicas de propulsão e que algumas caracteristicas angulares do movimento, como um menor ângulo de abdução do ombro nos estágios iniciais da propulsão, influenciam o desempenho no teste de velocidade.

Palavras-Chave: Esporte Adaptado; Biomecânica; Cinemetria; Performance.

\section{References}

1. Wang Y, Chen S, Limroongreungrat W, Change LS. Contributions of Selected Fundamental Factors to Wheelchair Basketball Performance. Med Sci Sports Exerc. 2004;37(1):130-7.

2. Woude LHV, Veeger HEJ, Dallmeijer AJ. Propulsão manual da cadeira de rodas. Rio de Janeiro: Guanabara Koogan; 2004.

3. Mason SB, van der Woude LHV, Goosey-Tolfrey V. The ergonomics of wheelchair configuration for optimal performance in the wheelchair court sports. Sports Med. 2013;43(1):23-38.

4. Goosey-Tolfrey V, Fowler NE, Campbell IG, Iwnicki SD. A kinetic analysis of trained wheelchair racers during two speeds of propulsion. Med Eng Phys. 2001;23(4):259-66.

5. Goosey-Tolfrey V, Foden E, Perret C, Degens H. Effects of inspiratory muscle training on respiratory function and repetitive sprint performance in wheelchair basketball players. Br J Sports Med. 2010;44(9):665-8.

6. Crespo-Ruiz BM, Del Ama-Espinosa AJ, Gil-Agudo AM. Relation between kinematic analysis of wheelchair propulsion and wheelchair functional basketball classification. Adapt Phys Activ Q. 2011;28(2):157-72.

7. Yanci J, Granados C, Otero M, et al. Sprint, agility, strength and endurance capacity in wheelchair basketball players. Biol Sport. 2015;32(1):71-8.

8. Vanlandewijck Y, Theisen D, Daly D. Wheelchair propulsion biomechanics: implications for wheelchair sports. Sports Med. 2001;31(5):339-67.

9. Okawa H, Tajima F, Makino K, et al. Kinetic factors determining wheelchair propulsion in marathon racers with paraplegia. Spinal Cord. 1999;37:542-7.

10. Bergamine E, Morelli F, Marchetti F, et al. Wheelchair propulsion biomechanics in junior basketball player: a method for the evaluation of the efficacy of a specific training program. Bio Med Res Int. 2015;(1):1-10.

11. Figueroa PJ, Leite NJ, Barros RML. A flexible software for tracking of markers used in human motion analysis. Comput Methods Programs Biomed. 2003;72(2):155-65.

12. Abdel-Aziz YI, Karara HM. Direct linear transformation from comparator coordinates into object space coordinates in closerange photogrammetry. Symposium on Close-Range Photogrammetry; 1971; Washington D.C., US. Washington D. C.: American Society of Photogrammetry; 1971. p. 1-18.

13. Cunha SA, Lima Filho EC. Methodology for the smooth of biomechanics data for functions distribution free. Braz J Biomech. 2003;1(6):23-8.

14. Gorgatti MG, Böhme MTS. Autenticidade científica de um teste de agilidade para indivíduos em cadeira de rodas. Rev Paul Educ Fís. 2003;17(1):41-50.

15. Aquino GC, Fortes TE, Rabelo RJ. Análise comparativa da agilidade de praticantes de basquetebol em cadeira de rodas. Movimentum. 2008;3(2):1-7.

16. Gil MS, Yanci J, Otero M, et al. The functional classification and field test performance in wheelchair basketball player. J Hum Kinet. 2015;46:219-30.

17. Yanci J, Iturricastillo A, Lozano L, Granados C. Análisis de la condición de jugadores nacionales de baloncesto en silla atendiendo a la clasificación funcional. RICYDE. 2015;11(40):175-85.

18. International Wheelchair Basketball Federation. Rules of wheelchair basketball [Internet]. Mies: IWBF; 2013 [cited 2013 Aug 1]. Available from: https://iwbf.org/rules-of-wheelchair-basketball/

19. Chiari L, Della Croce U, Leardini A, Cappozzo A. Human movement analysis using stereophotogrammetry. Part 2: Instrumental errors. Gait Posture. 2005;21(2):197-211. 
20. Hurd WJ, Morrow MM, Kaufman KR, An KN. Biomechanic evaluation of upper-extremity symmetry during manual wheelchair propulsion over varied terrain. Arch Phys Med Rehabil. 2008;89(10):1996-2002.

21. Vanlandewijck YC, Spaepen AJ, Lysens, R.J. Wheelchair propulsion efficiency: movement pattern adaptations to speed changes. Med Sci Sports Exerc. 1994;26(11):1373-81.

22. Dallmeijer AJ, Kappe YJ, Veeger DH, Janssen TW, van der Woude LH. Anaerobic power output and propulsion technique in spinal cord injured subjects during wheelchair ergometry. J Rehabil Res Dev. 1994;31(2):120-8.

23. Shimada SD, Robertson RN, Bonninger ML, Cooper RA. Kinematic characterization of wheelchair propulsion. J Rehabil Res Dev. 1998;35(2):210-8.

\begin{tabular}{r|l} 
ADDRESS & \\
Emanuel Messias Oliveira de Carvalho & Submitted: 25/11/2016 \\
Viana de Carvalho, 231 - 86057-970 & Review: 06/08/2017 \\
Londrina - PR - BRASIL & Accepted: 29/12/2017 \\
e-mail: manu_carvalho18@hotmail.com &
\end{tabular}

